\title{
ERK/AKT Inactivation and Apoptosis Induction Associate With Quetiapine-inhibited Cell Survival and Invasion in Hepatocellular Carcinoma Cells
}

\author{
YEN-JU LEE ${ }^{1,2}$, JING-GUNG CHUNG ${ }^{3}$, ZHAO-LIN TAN ${ }^{2,3}$, FEI-TING HSU ${ }^{3}$, \\ YU-CHANG LIU $2,4,5^{*}$ and SONG-SHEI LIN ${ }^{2 *}$ \\ ${ }^{1}$ Department of Emergency Medicine, Zuoying Branch of Kaohsiung \\ Armed Forces General Hospital, Kaohsiung, Taiwan, R.O.C.; \\ ${ }^{2}$ Department of Medical Imaging and Radiological Sciences, \\ Central Taiwan University of Science and Technology, Taichung, Taiwan, R.O.C.; \\ ${ }^{3}$ Department of Biological Science and Technology, China Medical University, Taichung, Taiwan, R.O.C.; \\ ${ }^{4}$ Department of Radiation Oncology, Chang Bing Show Chwan Memorial Hospital, Changhua, Taiwan, R.O.C.; \\ ${ }^{5}$ Department of Radiation Oncology, Show Chwan Memorial Hospital, Changhua, Taiwan, R.O.C.
}

\begin{abstract}
Background/Aim: Quetiapine, an atypical antipsychotic, has been encountered as a potential protective agent to suppress various types of tumor growth. However, the inhibitory mechanism of quetiapine in hepatocellular carcinoma (HCC) still remains unclear. The purpose of present study was to investigate the inhibitory mechanism of quetiapine on cell survival and invasion in HCC. Materials and Methods: Changes of apoptotic signaling, migration/invasion ability, and signaling transduction involved in cell survival and invasion were evaluated with flow cytometry, migration/invasion, and western blot assays. Results: Quetiapine inhibited cell proliferation and migration/invasion in SK-Hepl and Hep3B cells. Quetiapine induced extrinsic and intrinsic apoptotic pathways. Activation of extracellular signal-regulated kinases (ERK), protein kinase $B(A K T)$, nuclear factor kappa-lightchain-enhancer of activated $B$ cells $(N F-k B)$, expression of anti-apoptotic, and metastasis-associated proteins were
\end{abstract}

This article is freely accessible online.

*These Authors contributed equally to this study.

Correspondence to: Song-Shei Lin, Department of Medical Imaging and Radiological Sciences, Central Taiwan University of Science and Technology, Taichung, Taiwan, R.O.C. Tel: +886 422391647 ext. 7111, e-mail: sslin@ctust.edu.tw; Yu-Chang Liu, Department of Radiation Oncology, Show Chwan Memorial Hospital, Changhua 500, Taiwan, R.O.C. Tel: +886 422053366, ext. 2532, Fax: +886 422053366, e-mail: kevinyc.liu@gmail.com

Key Words: Quetiapine, hepatocellular carcinoma, ERK/AKT activation, apoptosis. decreased by quetiapine. Conclusion: The apoptosis induction, the decreased expression of ERK/AKT-mediated anti-apoptotic and the metastasis-associated proteins were associated with quetiapine-inhibited cell survival and invasion in HCC in vitro.

Antipsychotic medications are used for the treatment of patients with schizophrenia and other psychotic disorders (1). Recent epidemiological studies have focused on the relationship between cancer risk and the long-term use of antipsychotic drugs in patients with schizophrenia. Long-term antipsychotic treatment did not influence breast cancer risk, whereas risk of gastric or hepatocellular carcinoma (HCC) was reduced with antipsychotic use (2-4). Antipsychotic drugs have been shown to elicit anticancer response in various cancers. Sertindole, the second-generation antipsychotic drug, was presented to induce autophagyassociated apoptosis leading to tumor growth inhibition in breast cancer (5). Aripiprazole, the partial dopamine agonist used for treatment of schizophrenia, not only promoted cell growth inhibition but also increased sensitivity to chemotherapeutic agents in cancer stem cells (6).

Quetiapine, the atypical antipsychotic, augments release of neurotransmitters leading to improvement of schizophrenia-negative symptoms (7). In addition to antipsychotic effect, quetiapine as the multifunctional agent has been demonstrated to modulate several biological properties such as anti-inflammation, neuroprotection, and anti-cancer effect $(4,8,9)$. Quetiapine was presented to upregulate differentiation of glioma stem cells and enhance anti-glioma efficacy of temozolomide (TMZ) (10). Quetiapine also attenuated breast cancer-induced osteolysis through blocking differentiation of osteoclasts (11). Chen et 
A

SK-Hep1

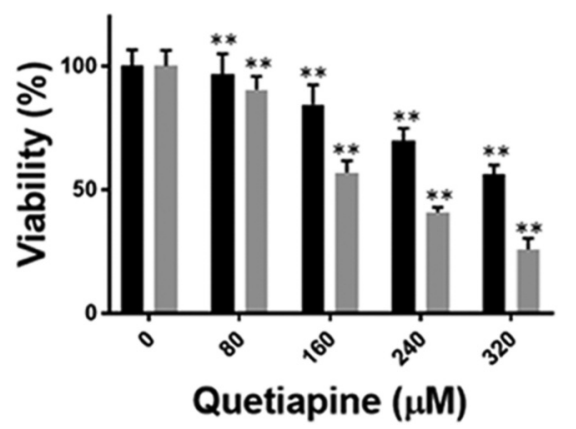

C
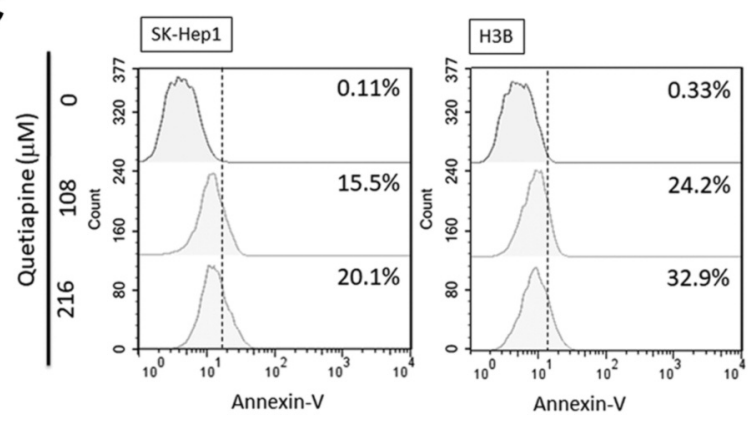

E

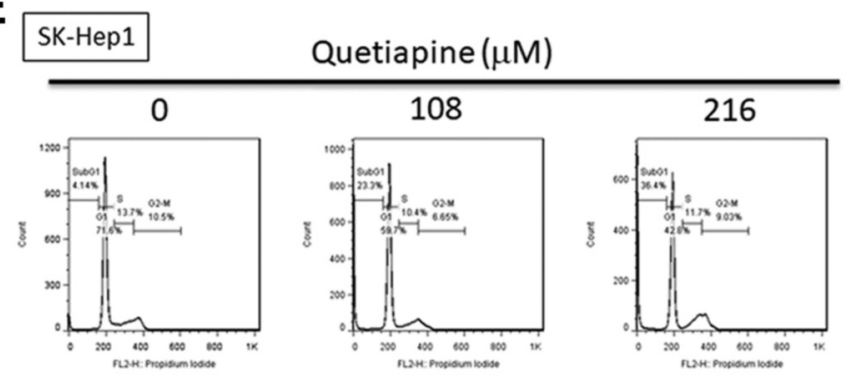

H3B

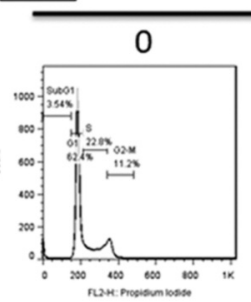

Quetiapine $(\mu \mathrm{M})$

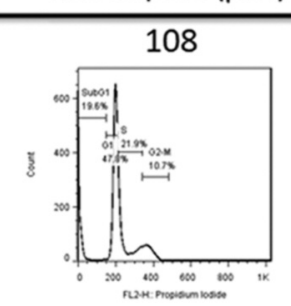

- $24 \mathrm{H}$

- $48 \mathrm{H}$
B

H3B

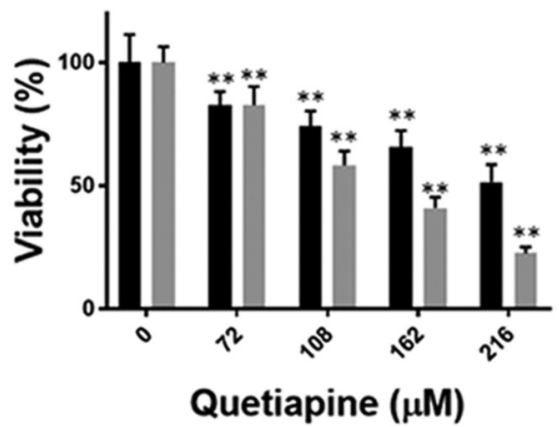

D

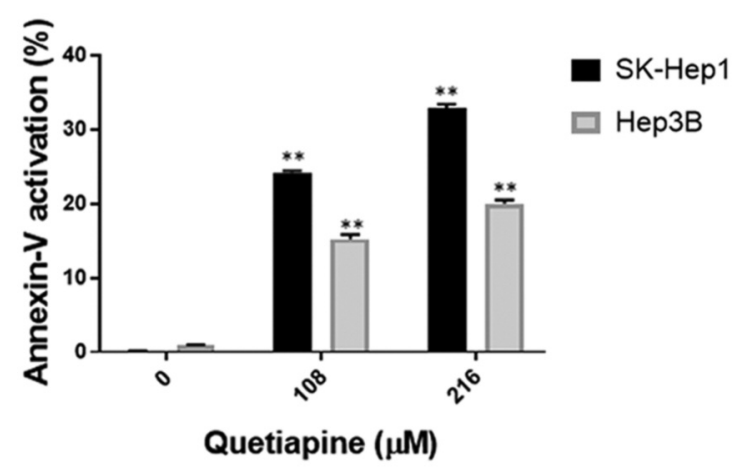

F

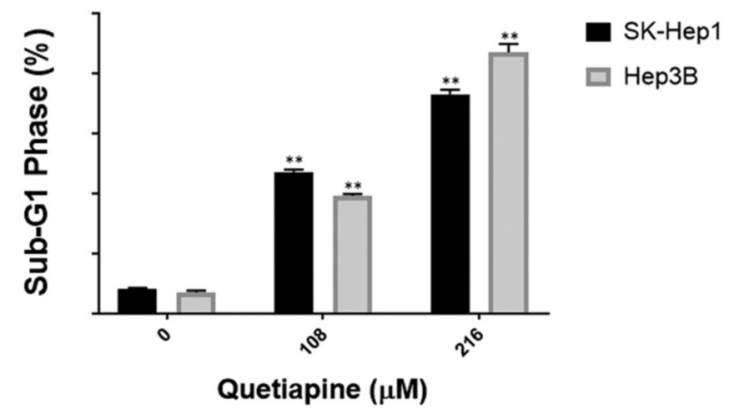



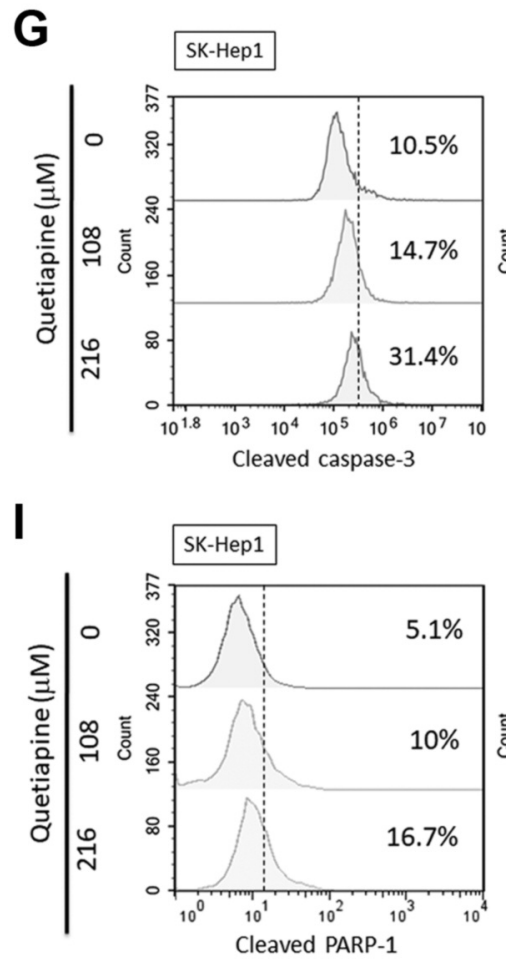

\section{H3B}
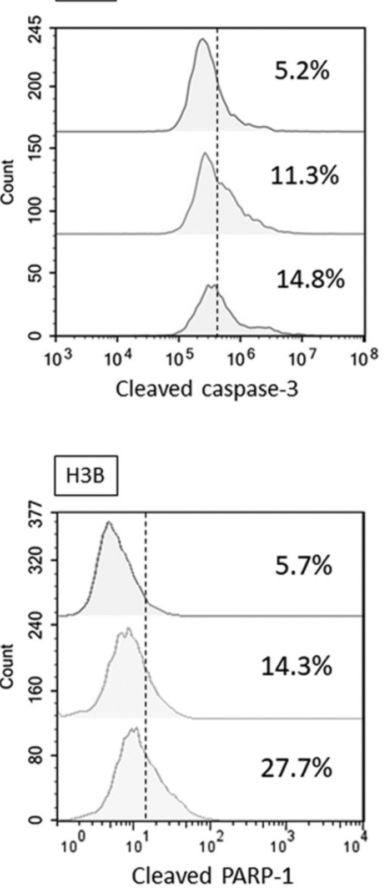

H

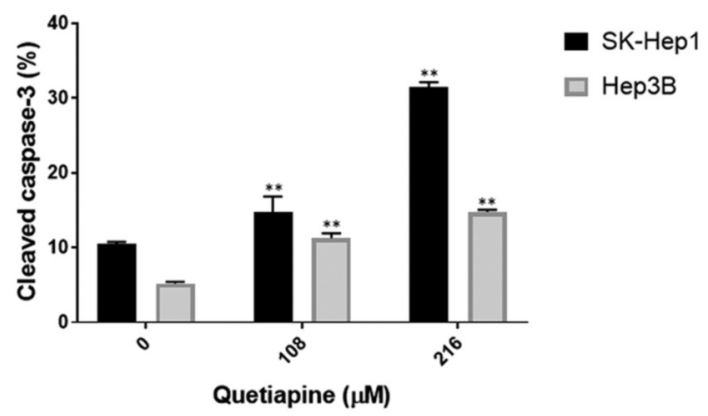

$\mathbf{J}$

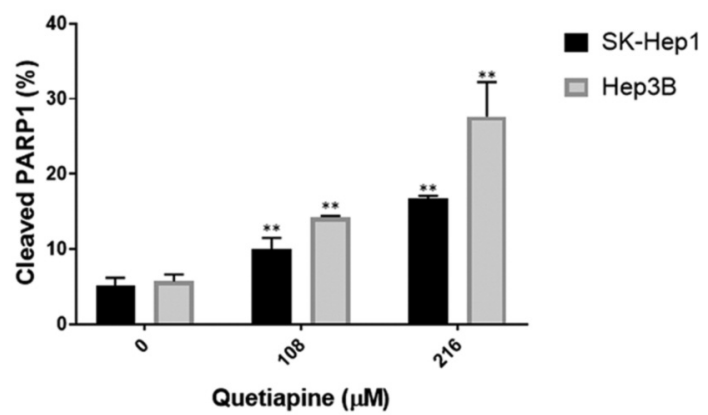

Figure 1. Induction of cytotoxicity and apoptosis by quetiapine in HCC. Cell viability of (A) SK-Hep1 and (B) Hep3B after quetiapine treatment are performed by MTT assay. (C) Annexin/PI staining pattern and (D) quantification data by flow cytometry after quetiapine treatment are displayed. After quetiapine treatment in HCC, $(E)$ cell cycle analysis, $(G)$ cleaved caspase-3 and (I) cleaved PARP-1 are also detected. Quantification results of $(F)$ sub- $G_{1},(H)$ cleaved caspase-3 and $(J)$ cleaved PARP-1 are displayed. ${ }^{*} p<0.05$, $* * p<0.01$ vs. $0 \mu M$ quetiapine.

al. found quetiapine as the protective agent that reduced HCC risk in patients with schizophrenia. Furthermore, quetiapine also inhibited tumor cell growth and invasion ability in HCC in vitro (4). However, the anti-HCC mechanism of quetiapine has not been elucidated. Therefore, the major purpose of the present study was to verify the inhibitory mechanism of quetiapine on cell survival and invasion in $\mathrm{HCC}$ in vitro.

\section{Materials and Methods}

Chemicals and reagents. Quetiapine was purchased from SigmaAldrich (St. Louis, MO, USA). DMEM high glucose was purchased from Tseng Hsiang Life science LTD. Fetal bovine serum (FBS), Lglutamine, and penicillin streptomycin (PS) were purchased from Gibco/Life Technologies (Carlsbad, CA, USA). 3,3'Dihexyloxacarbocyanine Iodide $\left(\mathrm{DiOC}_{6}\right)$ was bought from Enzo Life Sciences (Farmingdale, NY, USA). RNase was bought from Fermentas (St. Leon-Rot, Baden-Wurttemberg, Germany). Propidium iodide (PI), CaspGLOW ${ }^{\mathrm{TM}}$ Fluorescein Active Caspase3 Staining Kit, CaspGLOW ${ }^{\text {TM }}$ Red Active Caspase- 8 Staining Kit and Active Caspase-9 were all obtained from Biovision (Mountain View, CA, USA). MTT was purchased from Sigma-Aldrich. Matrigel and transwell ( $8-\mu \mathrm{m}$ pore size) were purchased from Selleck Chemicals (Houston, TX, USA) and Corning Life Sciences
(Tewksbury, MA, USA), respectively. MMP2 and MMP9 were bought from proteintech (Rosemont, IL, USA) and Millipore (Burlington, MA, USA), respectively. Further antibodies such as ERK (Thr202/Tyr204), ERK, AKT (Ser473), AKT, uPA, Survivin, MCL-1, VEGF, XIAP, $\beta$-actin were all bought from Elabscience (Houston, TX, USA).

Cell culture. Both SK-Hep1 and Hep3B human HCC cells used in this study were kindly provided from Professor Jing-Gung Chung's lab, China Medical University, Taichung, Taiwan, ROC. Both SK-Hep1 and Hep3B cells were incubated in Dulbecco's Modified Eagle Medium (DMEM) with high glucose, 10\% FBS, $2 \mathrm{mM}$ L-glutamine, $100 \mathrm{U} / \mathrm{ml}$ penicillin, and $100 \mathrm{mg} / \mathrm{ml}$ streptomycin and maintained in $10 \mathrm{~cm}$ culture dish at $37^{\circ} \mathrm{C}$ with $5 \%$ carbon dioxide at a humidified incubator (12). Cell culture reagents and media were all purchased from Thermo Fisher Scientific (Fremont, CA, USA).

3-(4,5-Dimethylthiazol-2-yl)-2,5-diphenyltetrazolium bromide (MTT) assay. SK-Hep1 and Hep3B cells were seeded into 96-well plates each well with 5,000 cells/well and incubated overnight. Cells were treated with different concentration of quetiapine $(0-320 \mu \mathrm{M})$ for 24 and $48 \mathrm{~h}$. After treatment, medium was replaced by MTT solution (MTT $5 \mathrm{mg} / \mathrm{ml}$ in PBS: DMEM Medium, 1:9) for another $4 \mathrm{~h}$ incubation. Then, MTT solution was replaced by dimethyl sulfoxide (DMSO) to dissolve purple crystal. Finally, the viable 
A
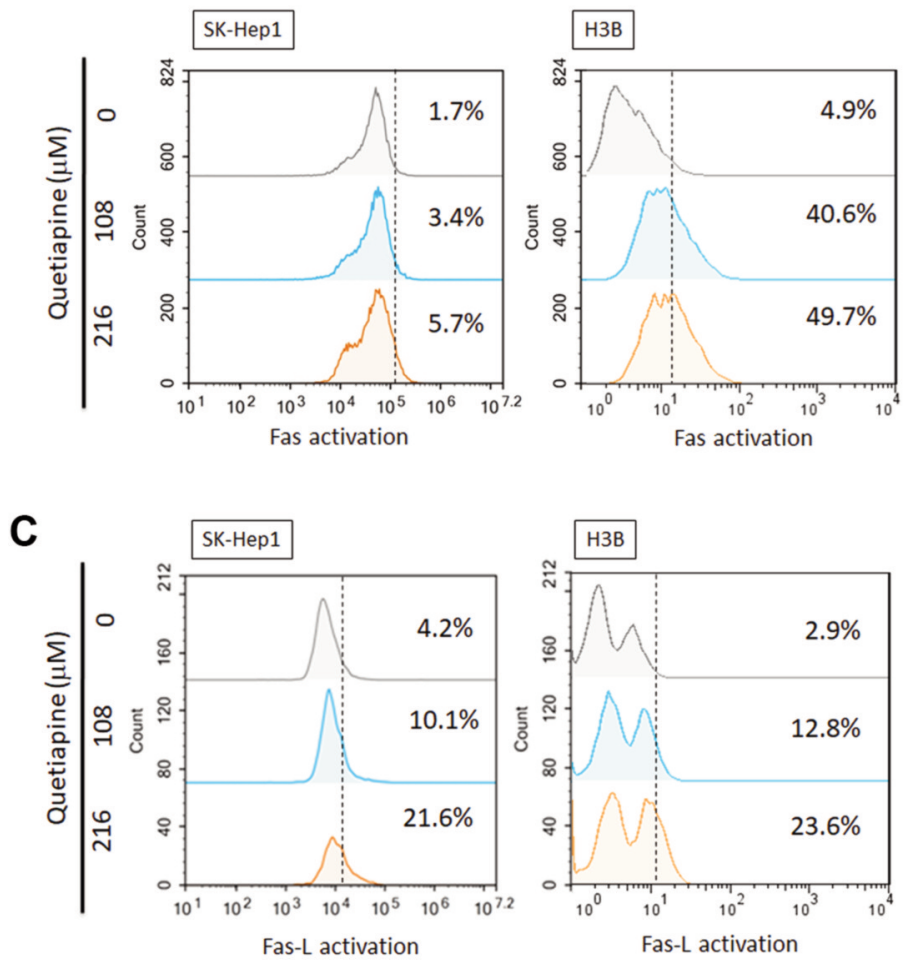

E

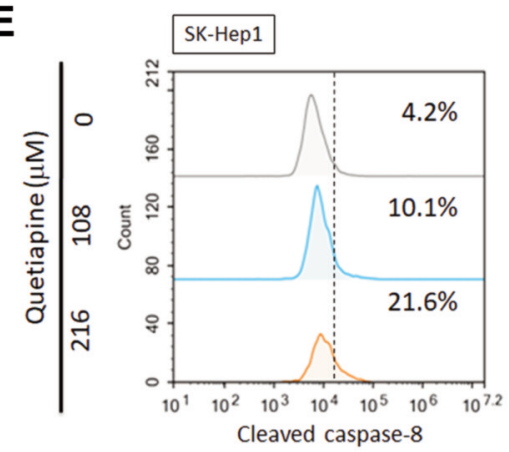

B

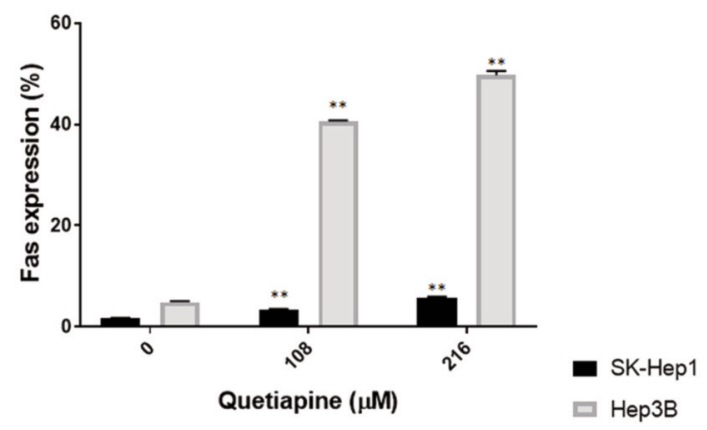

D

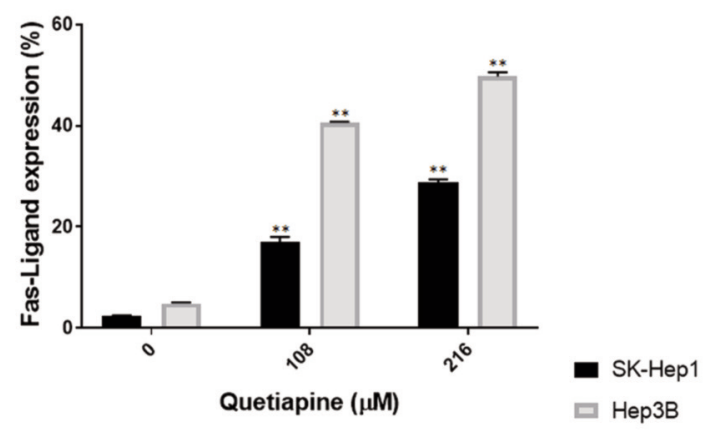

$\mathbf{F}$

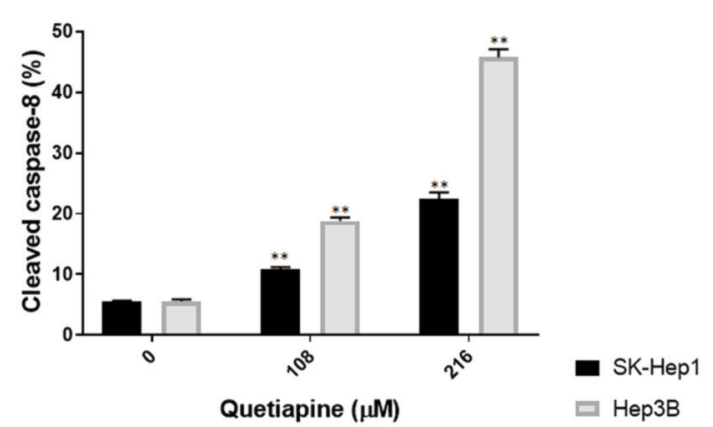

Figure 2. Activation of extrinsic apoptosis by quetiapine in HCC cells. (A) Fas activation pattern and (B) quantification bar chart are displayed after quetiapine treatment. (C) Fas-L activation pattern and (D) quantification bar chart are also shown. (E-F) The activation of cleaved caspase8 and relative quantification results are both showed. ${ }^{*} p<0.05,{ }^{*} p<0.01$ vs. $0 \mu \mathrm{M}$ quetiapine.

cells signal was detected by ELISA reader (SpectraMax iD3) at 570 $\mathrm{nm}$ wavelength. The max dosage of quetiapine used in this study was followed by the inhibitory concentration $30\left(\mathrm{IC}_{30}\right)$ and the inhibitory concentration $50\left(\mathrm{IC}_{50}\right)$ on SK-Hep1cells. This concentration $(0,108$ and $216 \mu \mathrm{M})$ was used in consequent experiments on both SK-Hep1 and Hep3B cells treatment.

Annexin V/propidium iodide (PI) staining. Both SK-Hep1 and Hep3B cells were seeded into 6 -well plates each well $5 \times 10^{5}$ cells and incubated overnight. Cells were treated with 0,108 and $216 \mu \mathrm{M}$ quetiapine for $48 \mathrm{~h}$. Cells were harvested by trypsin, stained with Annexin V/PI dye and incubated at $37^{\circ} \mathrm{C}$ for $30 \mathrm{~min}$. Cell population with Annexin V/PI-positive stain was detected and quantified by NovoCyte flow cytometry and NovoExpress ${ }^{\circledR}$ software (Agilent Technologies Inc., Santa Clara, CA, USA).

Cell cycle analysis. Both SK-Hep1 and Hep3B cells were seeded into 6-well plates each well $5 \times 10^{5}$ cells and incubated overnight. Cells were treated with 0,108 and $216 \mu \mathrm{M}$ quetiapine for $48 \mathrm{~h}$. Cells were harvested by trypsin, fixed with $75 \%$ ethanol by gently vortex and stored at $-20^{\circ} \mathrm{C}$ overnight. Cells were then washed with PBS and stained by $\mathrm{PI} / \mathrm{RNase}$ at $37^{\circ} \mathrm{C}$ for $30 \mathrm{~min}$. Cell cycle was finally detected and quantified by NovoCyte flow cytometry and NovoExpress ${ }^{\circledR}$ software. 
Cleaved Caspase-3, 8, 9, Fas, Fas-L, Ca ${ }^{2+}$, loss of mitochondria membrane potential ( DiOC $_{6}$ ) staining. Both SK-Hep1 and Hep3B cells were seeded into 6 -well plates each well $5 \times 10^{5}$ cells and incubated overnight. Cells were treated with 0,108 and $216 \mu \mathrm{M}$ quetiapine for $48 \mathrm{~h}$. Cells were harvested by trypsin, stained with Cleaved Caspase-3 (FITC), -8 (PE), -9 (FITC), Fas (FITC), Fas-L, $\mathrm{Ca}^{2+}(2.5 \mu \mathrm{g} / \mathrm{ml}$ Fluo-3/AM, FITC $), \operatorname{DiOC}_{6}(4 \mu \mathrm{M})$ dye, and followed by their own product protocols $(13,14)$.

Cleaved PARP-1 staining. Both SK-Hep1 and Hep3B cells were seeded into 6-well plates, each well with $5 \times 10^{5}$ cells and incubated overnight. Cells were treated with 0,108 and $216 \mu \mathrm{M}$ quetiapine for $48 \mathrm{~h}$. Cells were harvested by trypsin, fixed with $4 \%$ formaldehyde for $15 \mathrm{~min}$, permeabilized by ice-cold $100 \%$ methanol $30 \mathrm{~min}$ on ice, and freeze at $-20^{\circ} \mathrm{C}$ in $90 \%$ methanol overnight. Cells were finally washed by PBS and stained by PARP1 staining dye (1\% Bovine serum albumin and $0.3 \%$ Triton $\mathrm{X}$ in PBS with $1 \mu$ PARP-1 dye) (15).

Transwell migration/invasion assay. Both SK-Hep1 and Hep3B cells were treated with different dose of quetiapine $(0,108$ and 216 $\mu \mathrm{M})$ for $48 \mathrm{~h}$. After treatment, $3 \times 10^{5}$ cells were re-supended in serum-free medium and placed in top well of transwell. Then, inserted the transwell into 24-well plate with $700 \mu \mathrm{l}$ (/well) high serum medium ( $300 \mu \mathrm{l} \mathrm{FBS} \mathrm{in} 400 \mu \mathrm{l}$ medium) for $24 \mathrm{~h}$. Transwell membranes were then fixed with fixed buffer (acetid acid: methanol=1:3) for $15 \mathrm{~min}$, washed with PBS, and stained with $0.3 \%$ crystal violet for $10 \mathrm{~min}$. For invasion assay, $100 \mu \mathrm{l}$ matrigel mixture (serum-free medium: matrigel $=1: 1$ ) was added into transwell one day before cell inserted (16). Number of migration and invasion cells was quantified via ImageJ software version 1.50 (National Institutes of Health, Bethesda, MD, USA).

Western blotting. Both SK-Hep1 and Hep3B cells were seeded into $10 \mathrm{~cm}$ culture dish, incubated overnight, and treated with different doses of quetiapine $(0,108$ and $216 \mu \mathrm{M})$ for $48 \mathrm{~h}$. Cells were scraped in PBS, lysed by cell lysis buffer, followed with 10 mins' sonication and centrifuged with $12000 \mathrm{rpm}$ to extract total protein. Extracted proteins were quantified by BCA protein assay (Thermo Fisher Scientific). Proteins were mixed in $5 \times$ loading dye, separated by $8-12 \%$ SDS-PAGE and transferred to PVDF membranes. PVDF membranes were then added with primary antibodies overnight, and followed by $1 \mathrm{~h}$ secondary antibody incubation. The immunoreactivity bands were then visualized by Immobilon Western Chemiluminescent HRP Substrate kit (EMD Millipore) and detected by chemiluminescent image system (ChemiDoc-It 515, UVP, Upland, CA, USA).

Gene transfection. Both SK-Hep1 and Hep3B cells were seeded into 6-well plate for $3 \times 10^{5}$ transfected with $\mathrm{pNF}-\mathrm{kB} / \mathrm{luc} 2$ using JetPEI ${ }^{\mathrm{TM}}$ transfection kit (Illkirch, Bas-Rhin, France). The procedure was followed by commercial protocol and previous studies $(15,17)$. Cells with NF-kB/luc2 expression were named as SK-Hep1/NF$\kappa B / l u c 2$ and Hep3B/NF-kB/luc2.

Reporter gene assay. Both SK-Hep1/NF-kB/luc2 and Hep3B/NF$\kappa B / l u c 2$ were seeded into 96 -well plate each well with 5,000 cells and incubated overnight. Cells were treated with different doses of quetiapine $(0,72,108,162,216 \mu \mathrm{M})$ for $48 \mathrm{~h}$. After treatment, medium was replaced by D-luciferin solution $(500 \mu \mathrm{M}$ D-luciferin in $100 \mu \mathrm{l}$ PBS) and detected by IVIS100 Imaging System (Xenogen, Alameda,
CA, USA). Photon intensity emitted from cells was analyzed using living image ver.2.20.1 and normalized by cell viability (17).

Statistical analysis. Statistical analysis was performed by Microsoft excel one-way ANOVA and $p$-value $<0.05$ was defined as significant difference. Data are displayed as mean \pm standard deviation.

\section{Results}

Quetiapine induced cytotoxicity and apoptosis in HCC. To investigate the toxicity effect of quetiapine in $\mathrm{HCC}$, we evaluated cell viability by the MTT assay. As shown in Figure $1 \mathrm{~A}$ and $\mathrm{B}$, the cytotoxicity effect of quetiapine was found in SK-Hep1 and Hep3B cells in a dose- and timedependent manner. Then, we further investigated the apoptosis effect of quetiapine by Annexin/PI staining and cell-cycle assays. The percentages of early- and lateapoptosis populations were also found to be increased by quetiapine, as indicated in Figure 1C-D. As illustrated in Figure $1 \mathrm{E}-\mathrm{F}$, cells treated by quetiapine were markedly accumulated in the sub- $G_{1}$ phase in both SK-Hep1 and Hep3B cells. Additionally, the activation of cleaved caspase3 after quetiapine treatment is displayed in Figure 1G-H. Figure 1I-J indicated that quetiapine may also induce the percentage of cleavage of PARP-1 which was also used as a marker of apoptosis effect. In sum, both toxicity and apoptosis effects were triggered by quetiapine on HCC.

Quetiapine activated extrinsic apoptotic pathway of hepatocellular carcinoma. To further evaluate the detailed mechanism of quetiapine on apoptosis signaling, we performed Fas, Fas-L and caspase- 8 stain by cytometry. Fas activation was effectively increased by $48 \mathrm{~h}$ quetiapine treatment in SK-Hep1 and Hep3B cells (Figure 2A-B). The activation of Fas- $\mathrm{L}$ was also slightly increased by quetiapine, as shown in Figure 2C and D. Furthermore, caspase- 8 was recognized as the downstream effector of death receptormediated apoptosis pathway. Thus, we also performed cleaved caspase- 8 staining after $48 \mathrm{~h}$ quetiapine treatment on SK-Hep1 and Hep3B cells. In Figure 2E-F, the activation of cleaved caspase- 8 was obviously induced by quetiapine as compared to non-treated control.

Quetiapine triggered intrinsic apoptotic pathway of HCC. After confirming the effect of quetiapine on extrinsic apoptosis mechanism, we further investigated whether intrinsic apoptosis may be also triggered by quetiapine. As illustrated in Figure 3A-B, the percentage of cellular calcium was markedly increased by quetiapine treatment on both SKHep1 and Hep3B cells. Moreover, the loss of mitochondria potential $(\Delta \mathrm{m})$ was also found in quetiapine treatment group (Figure 3C-D). Caspase-9, an important downstream effector of mitochondria-dependent apoptosis, was also validated 
A
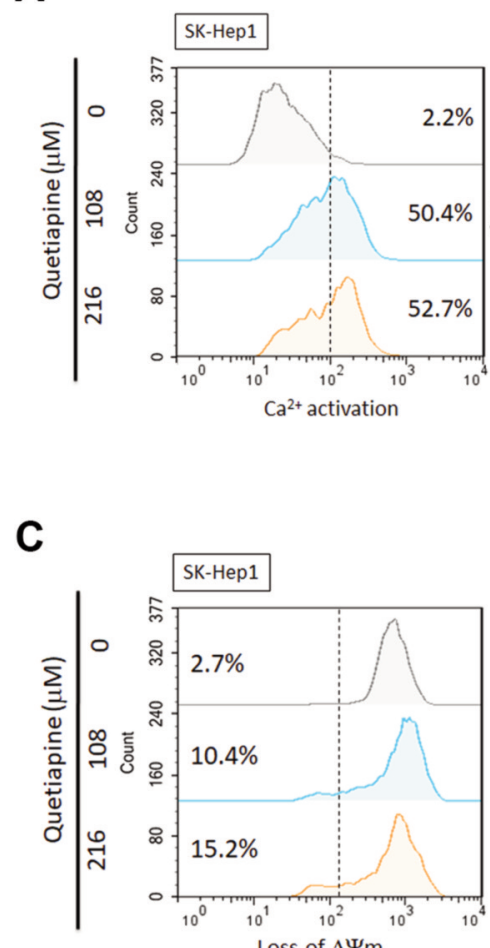

Loss of $\Delta \Psi \mathrm{m}$

\section{E}

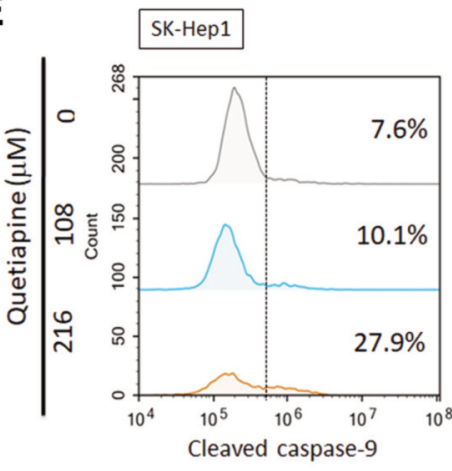

H3B
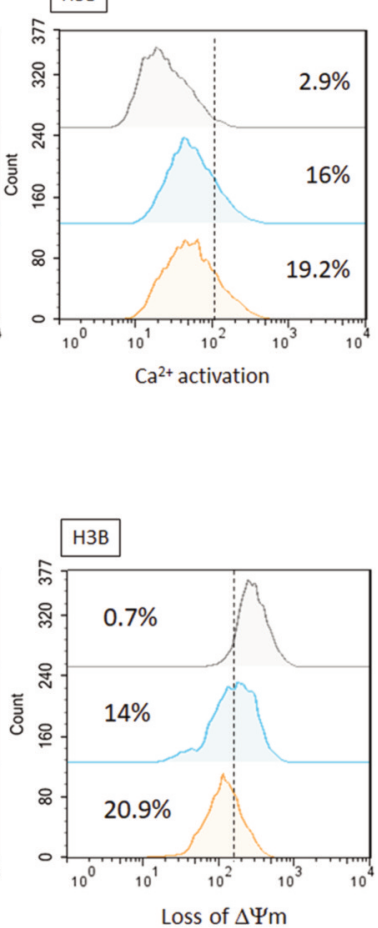

H3B

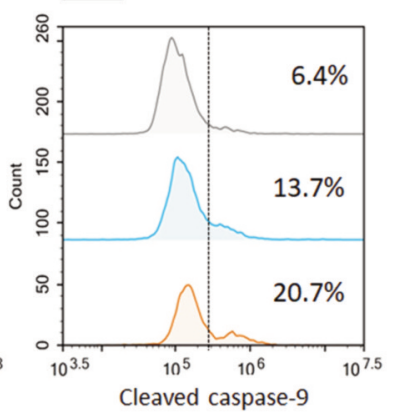

B

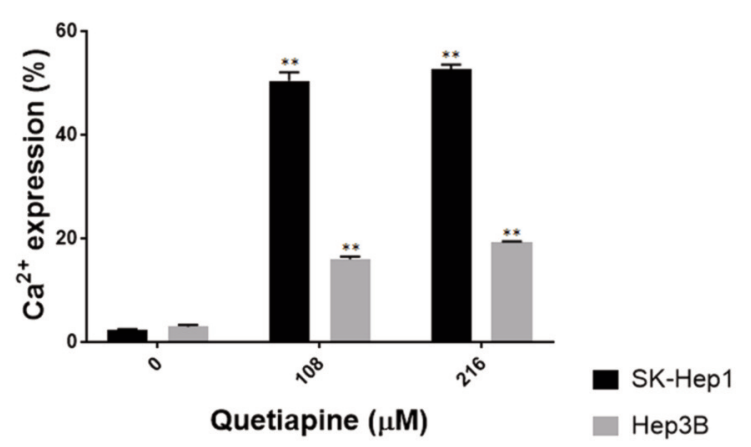

D

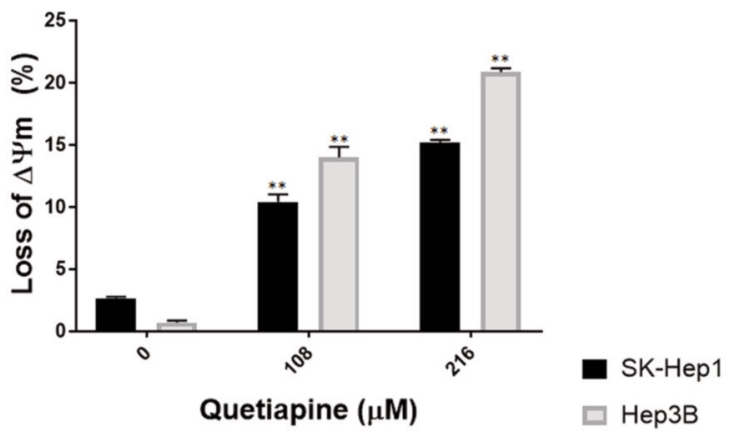

F

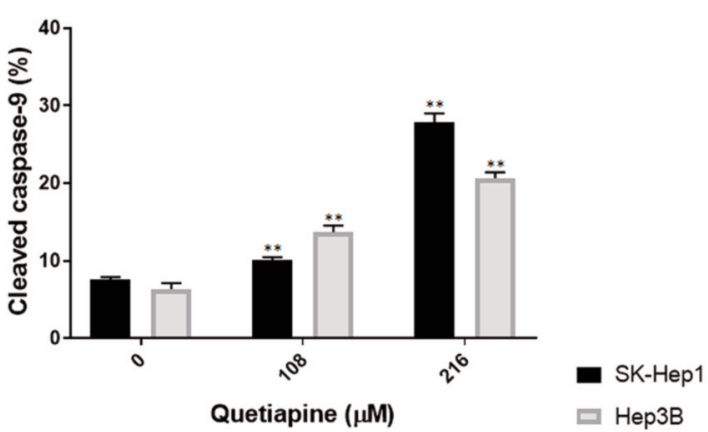

Figure 3. Activation of intrinsic apoptosis by quetiapine in HCC cells. (A) $\mathrm{Ca}^{2+}$ activation pattern and (B) quantification bar chart after quetiapine treatment. $(C-D)$ The loss of $\Delta m$ and quantification results after quetiapine treatment are presented. (E-F) The activation of cleaved caspase-3 and relative quantification results are shown. $* p<0.05$, $* * p<0.01$ vs. $0 \mu M$ quetiapine.

after quetiapine treatment on HCC. In figure $3 \mathrm{E}$ and $\mathrm{F}$, the activation pattern and quantification results both indicated the markedly induction of cleaved caspase- 9 by quetiapine treatment. The intrinsic apoptosis mechanism was also induced by quetiapine on HCC cells.

Quetiapine diminished both migration and invasion ability of HCC cells. Other than apoptosis induction, we also investigated whether the migration and invasion effects of HCC may be suppressed by quetiapine. Here, we used with or without matigel transwell migration/invasion assay to identify the effects of quetiapine on $\mathrm{HCC}$, respectively. Number of migration cells was effectively decreased by quetiapine treatment on both SK-Hep1 and Hep3B cells (Figure 4A-B). Furthermore, the invasion ability of HCC was also suppressed by quetiapine as indicated in figure $4 \mathrm{C}$ and 
A

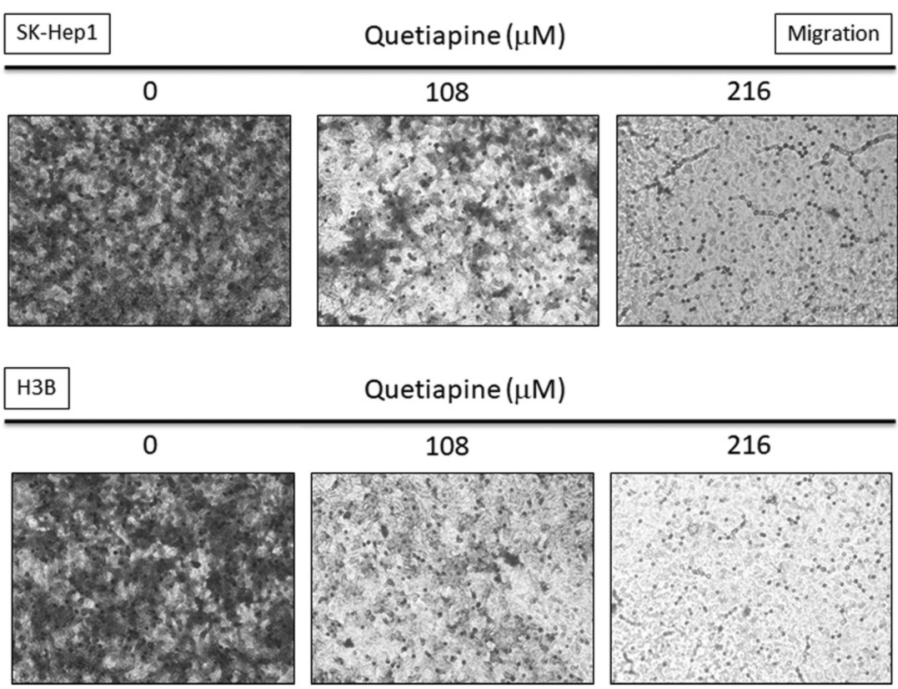

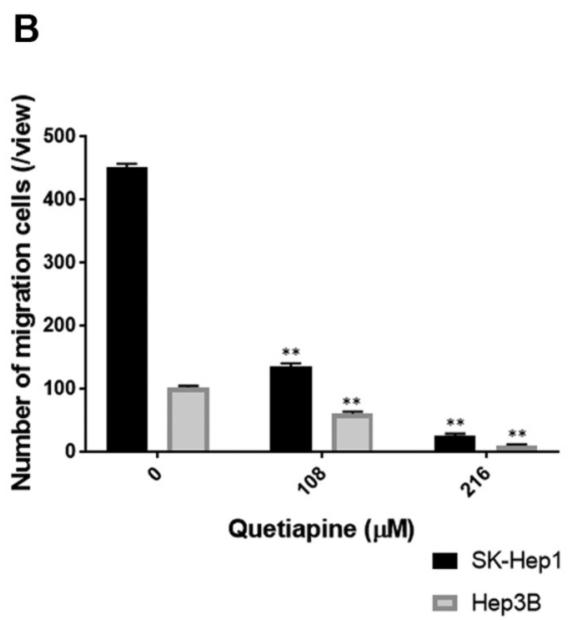

C
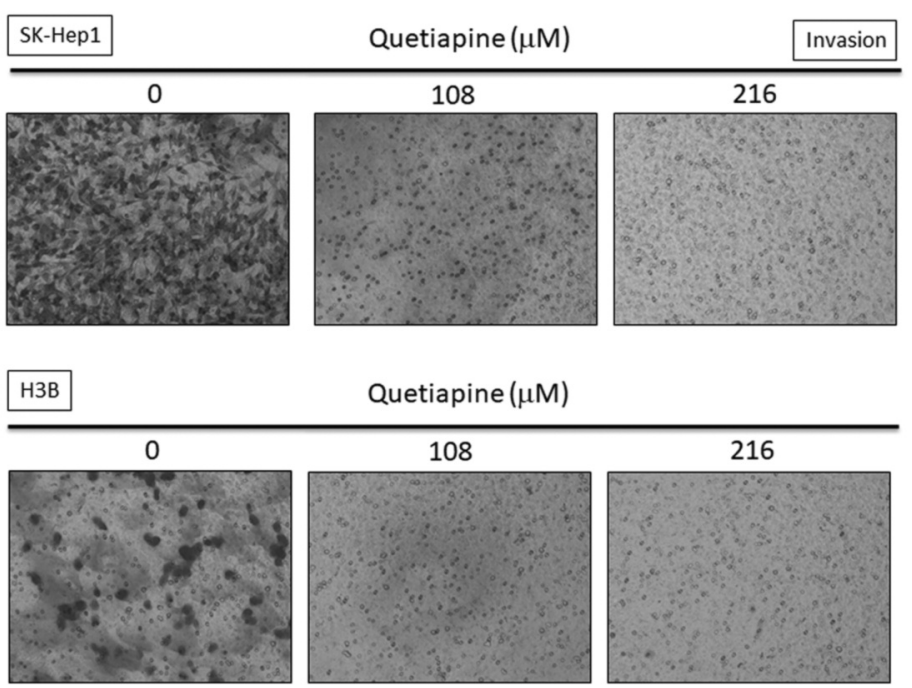

Quetiapine $(\mu \mathrm{M})$
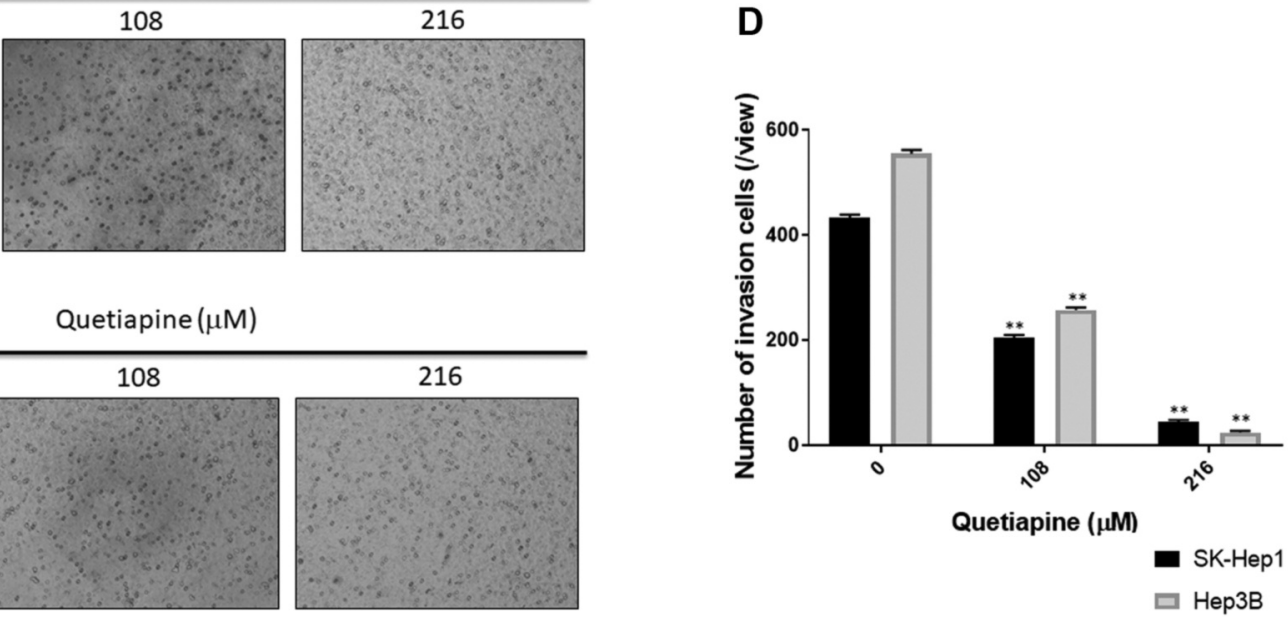

Figure 4. Inhibition of migration and invasion by quetiapine in HCC cells. (A) Migration transwell photos and (B) quantification results in SKHepl and Hep3B cells are displayed after quetiapine treatment. (C) Invasion transwell photos and (D) quantification results in SK-Hepl and Hep3B cells are also displayed. $* p<0.05, * * p<0.01$ vs. $0 \mu$ M quetiapine.

figure D. In conclude the migration and invasion capacity of HCC cells were both blocked by quetiapine.

Quetiapine suppressed ERK, AKT, NF-kB activation, expression of anti-apoptotic, and metastasis-associated proteins in HCC cells. We explored the effect of quetiapine on activation of oncogenic kinases and transcription factor involved in regulation of cell survival and invasion in HCC cells. Effect of quetiapine on phosphorylation of ERK and AKT was evaluated with western blotting. As shown in Figure 5A, quetiapine reduced phosphorylation of ERK and AKT by 35-95\% as compared to control group ( $0 \mu \mathrm{M}$ quetiapine). Then, we further investigated the effect of quetiapine on NF-kB activation by $\mathrm{NF}-\mathrm{kB}$ reporter gene assay. In Figure 5B-E presented quetiapine effectively decreased NF-kB activation by $30-75 \%$ as compared to control group in both SK-Hep1 and Hep3B cells. We further verified effect of quetiapine on anti-apoptotic and metastasisassociated proteins expression by Western blotting in both SKHep1 and Hep3B cells. As showed in 5F, Quetiapine diminished expression of anti-apoptotic proteins Survivin, XIAP, and MCL- 
A

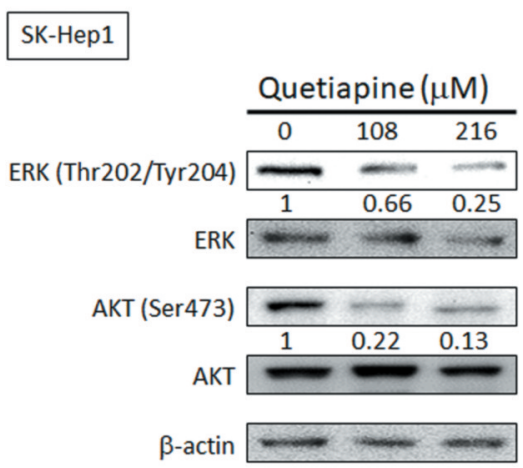

B

SK-Hep1

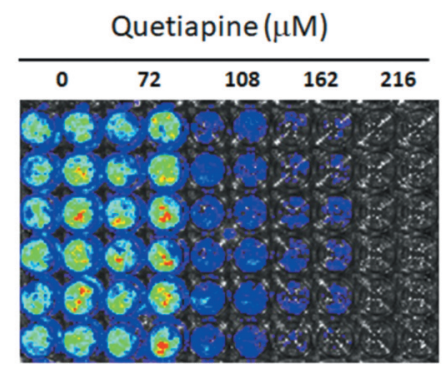

D

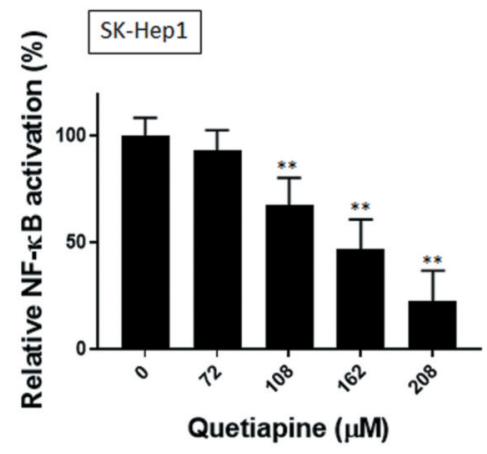

$\mathbf{F}$

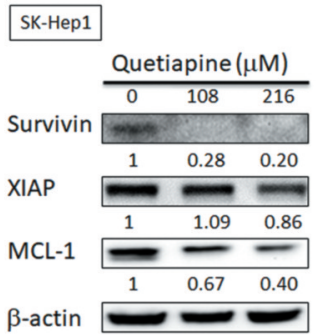

\section{H3B}

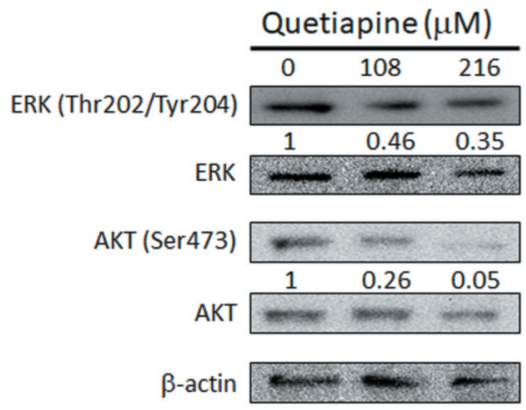

C

H3B

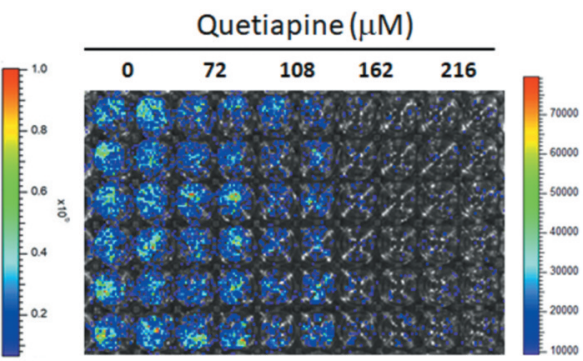

E

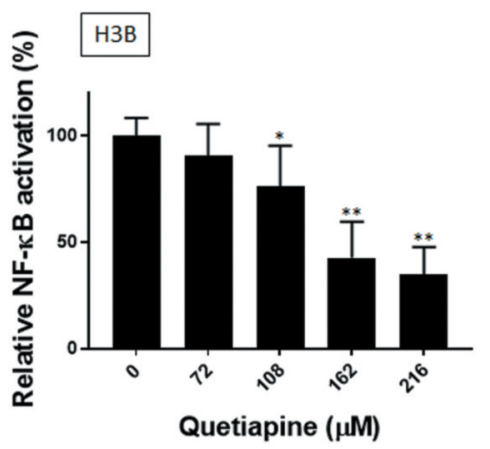

\section{G}

SK-Hep1

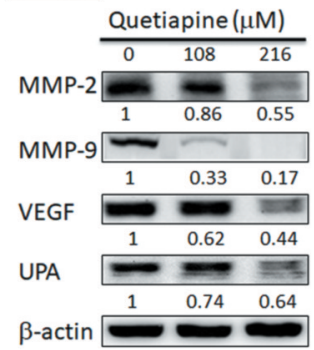

H3B

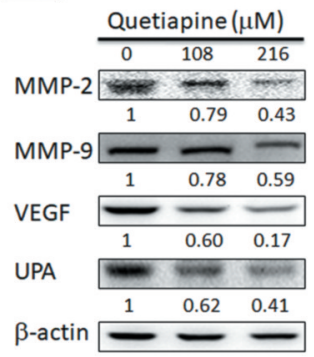

Figure 5. Inhibition of HCC progression-related proteins was associated with of AKT/ERK/NF-kB inactivation by quetiapine. (A) The phosphorylation pattern of ERK and $A K T$ are displayed. (B-C) $N F-k B$ activation pattern and $(D-E)$ quantification results after various doses of quetiapine treatment are shown. Both survival $(F)$ and anti-apoptosis related and invasion/migration $(G)$ and angiogenesis-related protein expression patterns after 0 , 108, $216 \mu \mathrm{M}$ quetiapine treatment on SK-Hep1 and Hep3B cells are displayed. $* p<0.05$, **p< $<0.01$ vs. $0 \mu$ M quetiapine. 
1 by $11-80 \%$ as compared to control group. In addition, quetiapine suppressed expression of metastasis-associated proteins such as MMP-2, MMP-9, VEGF and uPA by $14-80 \%$ as compared to control (Figure 5G).

\section{Discussion}

Rapid progression and high metastatic ability associate with worse survival in patients with $\operatorname{HCC}(18,19)$. Apoptosis negatively regulates tumor progression through extrinsic/ intrinsic apoptotic signaling transduction-induced cell death. Alternation of apoptotic and anti-apoptotic proteins triggers imbalance between cell death and cell proliferation in cancers. Decreased expression of apoptotic proteins and increased expression of anti-apoptotic proteins (Figure 5F) also potentiate resistance against anticancer agents-induced apoptosis in $\mathrm{HCC}(16,20,21)$.

Expression of apoptotic proteins caspase- 3 and Fas (CD95) were reduced and linked to drug resistance or poor survival in $\operatorname{HCC}(22,23)$. Anti-apoptotic proteins XIAP and MCL-1, as inhibitors of apoptotic signaling transduction, have been indicated to mediated acquired resistance to sorafenib (the anti-HCC drug) in HCC (24-26). Our results demonstrated quetiapine significantly induced apoptosis and promoted extrinsic/intrinsic apoptotic signaling transduction (Figures 2 and 3). Furthermore, as indicated by western blotting results, the expression of anti-apoptotic proteins XIAP, MCL-1, and survivin were diminished with quetiapine in SK-Hep1 and Hep3B cells (Figure 5F).

Overexpression of metastasis-associated proteins including MMP-9, MMP-2, uPA, and VEGF contribute to local invasion and distant metastasis through promotion of extracellular matrix (ECM) degradation and new blood vessel formation $(18,27,28)$. Cell and animal models presented the decreased expression of metastasis-associated proteins was involved in inhibition of invasion activity in HCC (29-31). Our results indicated that migration, invasion ability (Figure 4), and expression of metastasis-associated proteins (Figure 5G) were inhibited by quetiapine in HCC.

$\mathrm{NF}-\mathrm{KB}$ is the oncogenic transcription factor activated by oncogenic signaling pathways. Active NF-kB promotes the expression of proliferative, anti-apoptotic, inflammatory, epithelial mesenchymal transition, and metastasis-associated proteins encoded by NF-kB-related genes leading to tumor progression $(32,33)$. In previous studies, suppression of NF$\mathrm{KB}$ activation has been indicated to increase sensitivity to therapeutic agents and decrease cell invasion through downregulating expression of anti-apoptotic and metastasisassociated proteins in HCC in vitro and in vivo $(34,35)$. Our results also showed that quetiapine significantly reduced NF$\mathrm{kB}$ activation (Figure 5B-E).

In addition to NF- $\mathrm{KB}$ signaling, several oncogenic kinases, such as ERK and AKT participate in the promotion of cell survival and invasion through regulating expression of anti-apoptosis and metastasis-associated proteins in HCC. Suppression of both ERK and AKT activation reduce expression of anti-apoptotic and metastasis-associated proteins resulting in limitation of anti-apoptotic and invasion activity in $\operatorname{HCC}(13,36-38)$. Furthermore, in previous studies investgating PD98059, the ERK inhibitor, attenuated NF- $\mathrm{KB}$ activation, but the AKT inhibitor did not, in $\operatorname{HCC}(35,39)$. In our results, phosphorylation of ERK and AKT was alleviated with quetiapine treatment (Figure 5A).

Based on our results, we indicated that quetiapine may induce cytotoxicity and suppress tumor invasion/migration ability in HCC cells. We further indicated that quetiapine may trigger intrinsic and extrinsic apoptosis-related factors activation. Quetiapine may also suppress the phosphorylation of ERK and AKT in HCC cells. In conclusion, we provided information regarding the inhibitory mechanism of quetiapine on cell survival and invasion in HCC. We suggested that induction of apoptosis via extrinsic/intrinsic pathways, reduction of ERK/AKT-mediated anti-apoptotic (Survivin, XIAP, and MCL-1) and metastasis-associated proteins (MMP-9, MMP-2, uPA, and VEGF) expression are associated with quetiapine-inhibited cell survival and invasion in $\mathrm{HCC}$ in vitro.

\section{Funding}

This study was supported by a Grant from the Ministry of Science and Technology, Taipei, Taiwan (Grant number: MOST 108-2314B-039-007-MY3), Zuoying Branch of Kaohsiung Armed Forces General Hospital, Kaohsiung (Grant number: ZBH 108-37) and Chang Bing Show Chwan Memorial Hospital, Changhua (Grant number: BRD-18010), respectively. This work was also financially supported by the "Drug Development Center, China Medical University" from The Featured Areas Research Center Program within the framework of the Higher Education Sprout Project by the Ministry of Education (MOE) in Taiwan.

\section{Conflicts of Interest}

The Authors declare that they have no conflicts of interest with the contents of this article.

\section{Authors' Contributions}

Data curation: YJ Lee, ZL Tan, and FT Hsu. Funding acquisition: YJ Lee, FT Hsu and YC Liu. Writing, original draft: JG Chung, YJ Lee and FT Hsu; writing, review: JG Chung, YC Liu and SS Lin. All authors have read and agreed to the published version of the manuscript.

\section{Acknowledgements}

Experiments and data analysis were performed in part through the use of the Medical Research Core Facilities Center, Office of Research $\&$ Development at China Medical University, Taichung, Taiwan. 


\section{References}

1 Lally $\mathrm{J}$ and MacCabe JH: Antipsychotic medication in schizophrenia: A review. Br Med Bull 114: 169-179, 2015. PMID: 25957394. DOI: 10.1093/bmb/ldv017

2 Pottegard A, Lash TL, Cronin-Fenton D, Ahern TP and Damkier P: Use of antipsychotics and risk of breast cancer: A danish nationwide case-control study. Br J Clin Pharmacol 84: 21522161, 2018. PMID: 29858518. DOI: 10.1111/bcp.13661

3 Hsieh YH, Chan HL, Lin CF, Liang SH, Lu ML, McIntyre RS, Lee Y, Lin TC, Chiu WC and Chen VC: Antipsychotic use is inversely associated with gastric cancer risk: A nationwide population-based nested case-control study. Cancer Med 8: 4484-4496, 2019. PMID: 31183993. DOI: 10.1002/cam4.2329

4 Chen VC-H, Chan H-L, Hsu T-C, Lu M-L, Lee Y-C, Lee Y, Siow JY, McIntyre RS, Zhou AJ, Tzang B-S and Lee CT-C: New use for old drugs: The protective effect of atypical antipsychotics on hepatocellular carcinoma. Int J Cancer 144: 2428-2439, 2019. PMID: 30411796. DOI: 10.1002/ijc.31980

5 Zhang W, Zhang C, Liu F, Mao Y, Xu W, Fan T, Sun Q, He S, Chen Y, Guo W, Tan Y and Jiang Y: Antiproliferative activities of the second-generation antipsychotic drug sertindole against breast cancers with a potential application for treatment of breast-to-brain metastases. Sci Rep 8: 15753-15753, 2018. PMID: 30361678. DOI: 10.1038/s41598-018-33740-0

6 Suzuki S, Okada M, Kuramoto K, Takeda H, Sakaki H, Watarai $\mathrm{H}$, Sanomachi T, Seino S, Yoshioka $\mathrm{T}$ and Kitanaka C: Aripiprazole, an antipsychotic and partial dopamine agonist, inhibits cancer stem cells and reverses chemoresistance. Anticancer Res 36: 5153-5161, 2016. PMID: 27798875. DOI: 10.21873/anticanres.11085

7 Riedel M, Müller N, Strassnig M, Spellmann I, Severus E and Möller H-J: Quetiapine in the treatment of schizophrenia and related disorders. Neuropsychiatr Dis Treat 3: 219-235, 2007. PMID: 19300555. DOI: 10.2147/nedt.2007.3.2.219

8 Kim H, Bang J, Chang HW, Kim JY, Park KU, Kim SH, Lee KJ, Cho $\mathrm{CH}$, Hwang I, Park SD, Ha E and Jung SW: Antiinflammatory effect of quetiapine on collagen-induced arthritis of mouse. Eur J Pharmacol 678: 55-60, 2012. PMID: 22209881. DOI: $10.1016 /$ j.ejphar.2011.12.017

9 Yilmaz MB, Tonge M, Emmez H, Kaymaz F and Kaymaz M: Neuroprotective effects of quetiapine on neuronal apoptosis following experimental transient focal cerebral ischemia in rats. J Korean Neurosurg Soc 54: 1-7, 2013. PMID: 24044072. DOI: 10.3340/jkns.2013.54.1.1

10 Wang Y, Huang N, Li H, Liu S, Chen X, Yu S, Wu N, Bian XW, Shen HY, Li C and Xiao L: Promoting oligodendroglial-oriented differentiation of glioma stem cell: A repurposing of quetiapine for the treatment of malignant glioma. Oncotarget 8: 3751137524, 2017. PMID: 28415586. DOI: 10.18632/oncotarget. 16400

11 Wang H, Shen W, Hu X, Zhang Y, Zhuo Y, Li T, Mei F, Li X, Xiao L and Chu T: Quetiapine inhibits osteoclastogenesis and prevents human breast cancer-induced bone loss through suppression of the rankl-mediated mapk and nf-kappab signaling pathways. Breast Cancer Res Treat 149: 705-714, 2015. PMID: 25667102. DOI: 10.1007/s10549-015-3290-x

12 Tsai SC, Yang JS, Peng SF, Lu CC, Chiang JH, Chung JG, Lin MW, Lin JK, Amagaya S, Wai-Shan Chung C, Tung TT, Huang WW and Tseng MT: Bufalin increases sensitivity to akt/mtor- induced autophagic cell death in sk-hep-1 human hepatocellular carcinoma cells. Int J Oncol 41: 1431-1442, 2012. PMID: 22858649. DOI: $10.3892 /$ ijo.2012.1579

13 Chen JH, Chiang IT and Hsu FT: Protein kinase b inactivation is associated with magnolol-enhanced therapeutic efficacy of sorafenib in hepatocellular carcinoma in vitro and in vivo. Cancers (Basel) 12, 2019. PMID: 31905887. DOI: 10.3390/ cancers 12010087

14 Tsai JJ, Pan PJ, Hsu FT, Chung JG and Chiang IT: Glycyrrhizic acid modulates apoptosis through extrinsic/intrinsic pathways and inhibits protein kinase b- and extracellular signal-regulated kinase-mediated metastatic potential in hepatocellular carcinoma in vitro and in vivo. Am J Chin Med 48: 223-244, 2020. PMID: 32054305. DOI: 10.1142/S0192415X20500123

15 Chiang C-H, Chung J-G and Hsu F-T: Regorefenib induces extrinsic/intrinsic apoptosis and inhibits mapk/nf-kb-modulated tumor progression in bladder cancer in vitro and in vivo. Environ Toxicol 34: 679-688, 2019. PMID: 30801954. DOI: 10.1002/ tox.22734

16 Chen WT, Hsu FT, Liu YC, Chen CH, Hsu LC and Lin SS: Fluoxetine induces apoptosis through extrinsic/intrinsic pathways and inhibits erk/nf-kappab-modulated anti-apoptotic and invasive potential in hepatocellular carcinoma cells in vitro. Int J Mol Sci 20, 2019. PMID: 30754643. DOI: 10.3390/ ijms 20030757

17 Wu JY, Lin SS, Hsu FT and Chung JG: Fluoxetine inhibits DNA repair and nf-kb-modulated metastatic potential in non-small cell lung cancer. Anticancer Res 38: 5201-5210, 2018. PMID: 30194168. DOI: 10.21873/anticanres.12843

18 Zhang Y, Shen Y, Cao B, Yan A and Ji H: Elevated expression levels of androgen receptors and matrix metalloproteinase-2 and -9 in 30 cases of hepatocellular carcinoma compared with adjacent tissues as predictors of cancer invasion and staging. Exp Ther Med 9: 905-908, 2015. PMID: 25667651. DOI: 10.3892/etm.2014.2150

19 Chen J: The prognostic analysis of different metastatic patterns in advanced liver cancer patients: A population based analysis. PLoS One 13: e0200909, 2018. PMID: 30102707. DOI: 10.1371/journal.pone.0200909

20 Weng MC, Li MH, Chung JG, Liu YC, Wu JY, Hsu FT and Wang HE: Apoptosis induction and akt/nf-kappab inactivation are associated with regroafenib-inhibited tumor progression in non-small cell lung cancer in vitro and in vivo. Biomed Pharmacother 116, 2019. PMID: 31163381. DOI: 10.1016/ j.biopha.2019.109032

21 Fabregat I: Dysregulation of apoptosis in hepatocellular carcinoma cells. World J Gastroenterol 15: 513-520, 2009. PMID: 19195051. DOI: 10.3748/wjg.15.513

22 Fujikawa K, Shiraki K, Sugimoto K, Ito T, Yamanaka T, Takase $\mathrm{K}$ and Nakano T: Reduced expression of ice/caspase1 and cpp32/caspase3 in human hepatocellular carcinoma. Anticancer Res 20: 1927-1932, 2000. PMID: 10928128.

23 Ito Y, Monden M, Takeda T, Eguchi H, Umeshita K, Nagano H, Nakamori S, Dono K, Sakon M, Nakamura M, Tsujimoto M, Nakahara M, Nakao K, Yokosaki Y and Matsuura N: The status of fas and fas ligand expression can predict recurrence of hepatocellular carcinoma. Br J Cancer 82: 1211-1217, 2000. PMID: 10735508. DOI: 10.1054/bjoc.1999.1065

24 Chiang IT, Chen WT, Tseng CW, Chen YC, Kuo YC, Chen BJ, Weng MC, Lin HJ and Wang WS: Hyperforin inhibits cell 
growth by inducing intrinsic and extrinsic apoptotic pathways in hepatocellular carcinoma cells. Anticancer Res 37: 161-167, 2017. PMID: 28011486. DOI: 10.21873/anticanres.11301

25 Liu D, Fan Y, Li J, Cheng B, Lin W, Li X, Du J and Ling C: Inhibition of cflip overcomes acquired resistance to sorafenib via reducing er stressrelated autophagy in hepatocellular carcinoma. Oncol Rep 40: 2206-2214, 2018. PMID: 30066934. DOI: 10.3892/or.2018.6606

26 Hsu C, Lin LI, Cheng YC, Feng ZR, Shao YY, Cheng AL and Ou DL: Cyclin e1 inhibition can overcome sorafenib resistance in hepatocellular carcinoma cells through mcl-1 suppression. Clin Cancer Res 22: 2555-2564, 2016. PMID: 26603262. DOI: 10.1158/1078-0432.CCR-15-0499

27 Zheng Q, Tang ZY, Xue Q, Shi DR, Song HY and Tang HB: Invasion and metastasis of hepatocellular carcinoma in relation to urokinase-type plasminogen activator, its receptor and inhibitor. J Cancer Res Clin Oncol 126: 641-646, 2000. PMID: 11079728. DOI: $10.1007 / \mathrm{s} 004320000146$

28 Shim JH, Park JW, Kim JH, An M, Kong SY, Nam BH, Choi JI, Kim HB, Lee WJ and Kim CM: Association between increment of serum vegf level and prognosis after transcatheter arterial chemoembolization in hepatocellular carcinoma patients. Cancer Sci 99: 2037-2044, 2008. PMID: 19016764. DOI: 10.1111/ j.1349-7006.2008.00909.x

29 Huang CF, Teng YH, Lu FJ, Hsu WH, Lin CL, Hung CC, Tung JN, Hsieh YH and Liu CJ: Beta-mangostin suppresses human hepatocellular carcinoma cell invasion through inhibition of mmp-2 and mmp-9 expression and activating the erk and jnk pathways. Environ Toxicol 32: 2360-2370, 2017. PMID: 28722351. DOI: $10.1002 /$ tox.22449

30 Ghosh A, Dasgupta D, Ghosh A, Roychoudhury S, Kumar D, Gorain M, Butti R, Datta S, Agarwal S, Gupta S, Dhali G, Chowdhury A, Schmittgen T, Kundu G and Banerjee S: Mirna199a-3p suppresses tumor growth, migration, invasion and angiogenesis in hepatocellular carcinoma by targeting vegfa, vegfr1, vegfr2, hgf and mmp2. Cell Death \& Disease 8: e2706, 2017. PMID: 28358369. DOI: 10.1038/cddis.2017.123

$31 \mathrm{Wu}$ MH, Chiu YF, Wu WJ, Wu PL, Lin CY, Lin CL, Hsieh YH and Liu CJ: Synergistic antimetastatic effect of cotreatment with licochalcone a and sorafenib on human hepatocellular carcinoma cells through the inactivation of $\mathrm{mkk} 4 / \mathrm{jnk}$ and upa expression. Environ Toxicol 33: 1237-1244, 2018. PMID: 30187994. DOI: $10.1002 /$ tox. 22630
32 Xia Y, Shen S and Verma IM: Nf-kappab, an active player in human cancers. Cancer Immunol Res 2: 823-830, 2014. PMID: 25187272. DOI: $10.1158 / 2326-6066$.CIR-14-0112

33 Huang SS, Deng JS, Lin JG, Lee CY and Huang GJ: Antiinflammatory effects of trilinolein from panax notoginseng through the suppression of nf-kappab and mapk expression and proinflammatory cytokine expression. Am J Chin Med 42: 14851506, 2014. PMID: 25482678. DOI: 10.1142/S019241 $5 \mathrm{X} 14500931$

34 Liu YC, Wu RH and Wang WS: Regorafenib diminishes the expression and secretion of angiogenesis and metastasis associated proteins and inhibits cell invasion via nf-kappab inactivation in sk-hep1 cells. Oncol Lett 14: 461-467, 2017. PMID: 28693192. DOI: 10.3892/ol.2017.6142

35 Hsu FT, Liu YC, Chiang IT, Liu RS, Wang HE, Lin WJ and Hwang JJ: Sorafenib increases efficacy of vorinostat against human hepatocellular carcinoma through transduction inhibition of vorinostat-induced erk/nf-kappab signaling. Int J Oncol 45: 177-188, 2014. PMID: 28693192. DOI: 10.3892/ol.2017.6142

36 Fleischer B, Schulze-Bergkamen H, Schuchmann M, Weber A,Biesterfeld S, Müller M, Krammer PH and Galle PR: Mcl-1 is an anti-apoptoticfactor for human hepatocellular carcinoma. Int J Oncol 28: 25-32, 2006. PMID: 16327976.

37 Hua H, Zhu Y and Song YH: Ruscogenin suppressed the hepatocellularcarcinoma metastasis via PI3K/Akt/mTOR signaling pathway. Biomed Pharmacother 101: 115-122, 2018. PMID: 29477471. DOI:10.1016/j.biopha.2018.02.03138.

38 Lee KC, Tsai JJ, Tseng CW, Kuo YC, Chuang YC, Lin SS, Hsu FT:Amentoflavone Inhibits ERK-modulated Tumor Progression in HepatocellularCarcinoma In Vitro. In Vivo 32: 549554.PMID: 29695559. DOI: 10.21873/invivo.1127439.

39 Tsai JJ, Pan PJ and Hsu FT: Regorafenib induces extrinsic andintrinsic apoptosis through inhibition of ERK/NF- $x \mathrm{~B}$ activation inhepatocellular carcinoma cells. Oncol Rep 37: 10361044,2017. PMID: 28000898. DOI: 10.3892/or.2016.5328

Received May 31, 2020

Revised June 17, 2020

Accepted June 19, 2020 